\title{
Molecular characterization and differentiation of five horse breeds raised in Algeria using polymorphic microsatellite markers
}

\author{
N. Berber ${ }^{1}$, S. Gaouar ${ }^{2}$, G. Leroy ${ }^{3,4}$, S. Kdidi ${ }^{5,6}$, N. Tabet Aouel ${ }^{7}$ \& N. Saïdi Mehtar ${ }^{1}$ \\ 1 Laboratoire de Génétique Moléculaire et cellulaire, Université des sciences et de la technologie d’Oran - mohamed Boudiaf- USTOMB, BP 1505 El \\ M'naouer, Oran, Algeria \\ 2 Département de biologie, Université de Tlemcen, Telemcen, Algeria \\ 3 AgroParisTech, UMR1236 Génétique et Diversité Animales, Paris, France \\ 4 INRA, UMR1236 Génétique et Diversité Animales, Jouy-en-Josas, France \\ 5 Livestock \& Wildlife Laboratory, Arid Lands Institute, Medenine, Tunisia \\ 6 Laboratory of Genetics, Immunology and Human Pathology, Faculty of Sciences, Tunis-El Manar University, Tunisia, Tunisia \\ 7 Département de biotechnologie, Université d'Oran Es-sénia, Oran, Algeria
}

\section{Keywords}

Barb; Arab-Barb; genetic distances; factorial correspondence analysis; structure analysis.

\section{Correspondence \\ N. Berber, Laboratoire de Génétique \\ Moléculaire et cellulaire, Université des sciences et de la technologie d'Oran - mohamed Boudiaf- USTOMB, BP 1505 El M'naouer, Oran, Algeria. \\ Tel: +213 646015 24; \\ E-mail: nima.berber@gmail.com}

Received: 7 February 2014;

accepted: 16 April 2014

\section{Summary}

In this study, genetic analyses of diversity and differentiation were performed on five horse breeds raised in Algeria (Barb, Arab-Barb, Arabian, Thoroughbred and French Trotter). All microsatellite markers were highly polymorphic in all the breeds. A total of 123 alleles from 14 microsatellite loci were detected in 201 horses. The average number of alleles per locus was the highest in the Arab-Barb horses (7.86) and lowest in the thoroughbred breed (5.71), whereas the observed and expected heterozygosities per breed ranged from 0.71 (Thoroughbred) to 0.752 (Barb) and 0.71 (Thoroughbred) to 0.77 (Arab-Barb), respectively. The genetic differentiation between the breeds was significant $(p<0.01)$ based on the infinitesimal model $\left(F_{\mathrm{ST}}\right)$. Three different approaches for evaluating the genetic relationships were applied. Genetic distances, the factorial correspondence analysis and structure analysis showed that a significant amount of genetic variation is maintained in the native horse populations and the other breeds. The Barb and Arab-Barb breeds seem to be the most genetically related and support the decision to consider the breeds as same population.

\section{Introduction}

In Algeria, the horse occupies an important space in the history, the culture and tradition of the society. Horses also represent an important market, with nearly 100000 horses according to the data of the Algerian Ministry of Agriculture, Fisheries and Food (Rahal 2005). The great majority of these horses are commonly identified as Barb and Arab-Barb. These two breeds are from the coastal regions of North Africa. They are generally used in the fantasia (traditional exhibition of horsemanship in the Maghreb performed during cultural festivals), as well as in the equestrian sports. There are an approximately of 10000 heads belonging to the Barb breed and 80000 Arab-Barb (Kadri 2006).

In 1886, the first Algerian studbook of the Barb horse has been established. The Tunisian and Moroccan studbooks have followed in 1896 and 1914, respectively (Kadri 2006). Currently, there is an international commitment to promote and preserve the Barb breed. As well, Algeria created the World Organization of the Barb Horse OMCB in June 1987. This organization counts today eight countries that are, in 
addition to the countries of origin (Algeria, Morocco and Tunisia), France, Belgium, Germany, Switzerland and Luxembourg (Kadri 2006). The Arab-Barb is the predominant breed in Algeria. This breed is the creation of Tiaret broodmares in 1877, by crossing between Barb and Arabian horses (Rahal 2005). The breed is raised to combine the hardiness, the endurance and the stamina of the Barb, to the elegance and the speed of the Arabian.

In addition to these two autochthonous breeds, we also distinguish Arabian breed, Thoroughbred and the French trotters, mainly used in equestrian sporting events of dressage and show jumping. For several decades, these imported breeds distributed unevenly on the Algerian territory and they adapt the most in mountainous regions and arid territories of North Africa (Kadri 2006).

In animal breeding, genetic characterization is the first step in breed conservation and may have implications for future breeding strategies and management plans. Among molecular markers, microsatellites are considered suitable for biodiversity evaluation, owing to their ubiquitous presence throughout the mammalian genome, codominant inheritance and high degree of polymorphism, and these markers have been successfully used in parentage and relatedness tests in horses (Bowling et al. 1997).

Genetic diversity within and among horse breeds around the world has been analysed by microsatellites, including the Spanish Celtic breeds (Cañon et al. 2000), Polish breeds (Zabek et al. 2005), Brazilian breeds (Lippi \& Mortari 2003), Portuguese breeds (Luís et al. 2007), French breeds (Leroy et al. 2009) and Indian horse breeds (Behl et al. 2007). However, the genetic relationships of horse populations in Algeria have not been investigated using microsatellites.

This research is the first applying molecular markers to characterize the horse breeds in Algeria. The aim of this study was to (i) analyse the genetic diversity of five horse breeds raised in Algeria using a set of microsatellite markers, (ii) determinate their genetic relationship and (iii) characterize geographical and genetic differentiation between Barb and Arab-Barb breeds at different spatial sites in Algeria.

\section{Materials and methods}

\section{Population samples and DNA isolation}

Blood samples from 201 animals were collected from five domesticated horse breeds from their respective areas of distribution (Figure 1). The breeds involved and their sample sizes were as follows: Arab-Barb $(\mathrm{AB}, \mathrm{N}=55)$, Arabian $(\mathrm{AR}, \mathrm{N}=57)$, Barb (BA, $\mathrm{N}=41$ ), Thoroughbred (PS, $\mathrm{N}=22$ ) and French Trotter $(\mathrm{TF}, \mathrm{N}=26)$. The individuals chosen were registered in the breed's studbook, and we avoided closely related animals. Approximately $10 \mathrm{ml}$ of blood per animal was collected aseptically into EDTA (0.5 mm, $\mathrm{pH}$ 8.0) coated vacutainers, and genomic DNA was extracted from whole blood following the salting out procedure (Miller et al. 1988). DNA samples of these animals were provided by the laboratory of genetics molecular and cellular, Oran, Algeria.

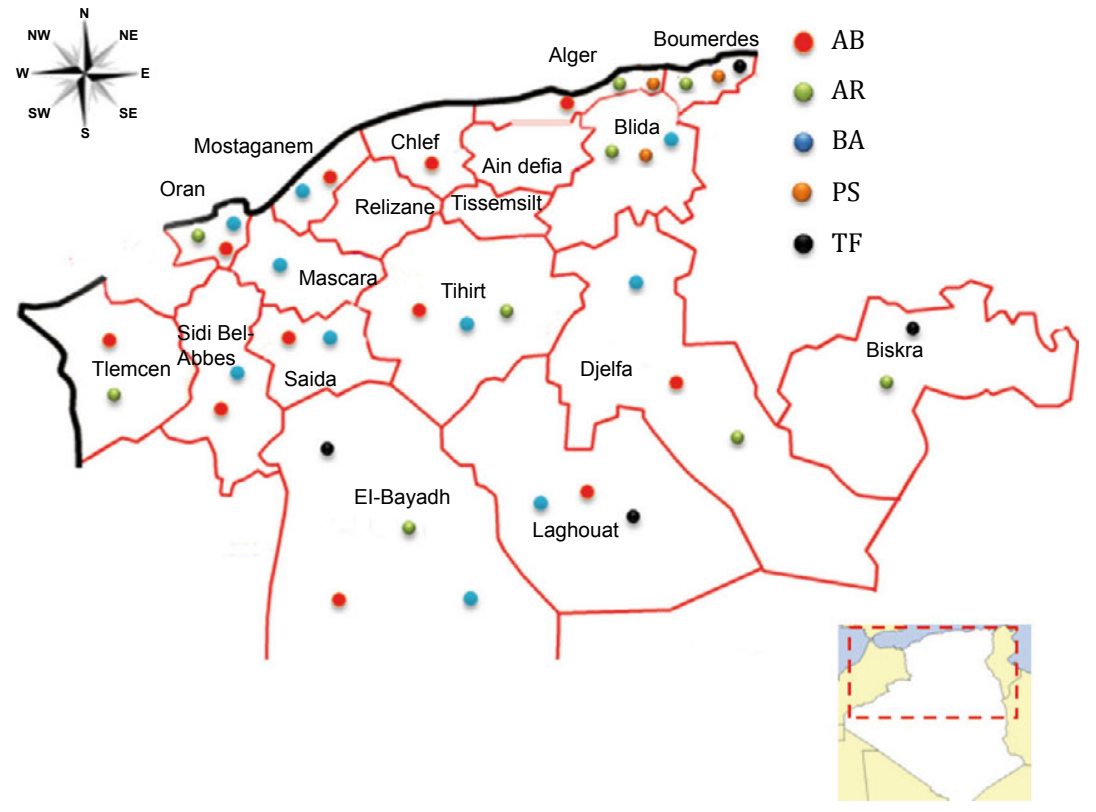

Figure 1 Geographical location of five horse breeds sampled in this study. Population abbreviations are found in Table 1. 


\section{Microsatellite markers}

Fourteen microsatellite markers were selected for this study. These microsatellite markers have been recommended for individual identification and parentage verification of equines by the International Society for Animal Genetics (ISAG). The genotyping assays of microsatellites were performed in LABOGENA Laboratory, Paris, France.

\section{Multiplex PCR conditions}

In our study, we amplified fourteen microsatellites in two multiplex using fluorescently labelled primers. The first multiplex MPl included microsatellites AHT4, AHT5, ASB2, HMS1, HMS3, HMS6, HMS7, HTG4, and HTG6, HTG10,VHL20. And the second MP2 was composed of ASB17, ASB23, HMS2 and HTG10. The thermocycling conditions included an initial denaturation at $95^{\circ} \mathrm{C}$ for $15 \mathrm{~min}$, followed by 30 cycles of $30 \mathrm{~s}$ at $94^{\circ} \mathrm{C}, 90 \mathrm{~s}$ at $58^{\circ} \mathrm{C}$ annealing temperature and $1 \mathrm{~min}$ at $72^{\circ} \mathrm{C}$. A final elongation step was carried out at $60^{\circ} \mathrm{C}$ for $30 \mathrm{~min}$. The amplified products were denatured with formamide, and PCR products were detected by capillary electrophoresis using an ABI Prism 3730 DNA Genetic Analyzer (Applied Biosystems, USA). Size analyses of DNA fragments separated were performed with GENOTYPE software Ver.3.7 (Applied Biosystems). The internal size standard GENESCAN-LIZ 500 (Applied Biosystems) was used for sizing alleles.

\section{Computation and statistical analysis}

Allelic frequencies and number of alleles per locus observed heterozygosity $\left(H_{\mathrm{O}}\right)$ and unbiased expected heterozygosity $\left(H_{\mathrm{e}}\right)$ were calculated across loci and populations using the GENETIX software version 4.04 (Belkhir et al. 2001). Representation of the genetic relationships among tested populations was performed using FCA approach (Lebart et al. 1984) as implemented by the same software. Wright F-statistics $\left(F_{\mathrm{IT}}, F_{\mathrm{ST}}\right.$ and $\left.F_{\mathrm{IS}}\right)$ and allelic richness $\left(R_{\mathrm{t}}\right)$ were calculated for each locus and across the genome using FSTAT 2.9.3 (Goudet 2001). A hierarchical analysis of variance was carried out using an analysis of molecular variance (AMOVA) approach implemented in the software ARLEQUIN version 3.01 package (Excoffier et al. 2005).

The Hardy-Weinberg equilibrium test (HWE) was performed with the GENEPOP 4.0 software (Raymond 8 Rousset 1995) using exact tests and sequential Bonferroni correction. The gene flow value $\left(N_{\mathrm{m}}\right)$ was also computed using the same software. PHYLIP 3.5 statistical package (Felsenstein 1989) was used to calculate genetic distances and to obtain bootstrap procedures and trees. Bootstraps' values were computed more than 1000 replicates, and Spltstree 4.0 software (Huson \& Bryant 2006) was used to visualize the diagrams.

The genetic structure of the populations was analysed by Bayesian clustering methods developed by Pritchard using the software structure 2.1 (Pritchard et al. 2000). An admixture model and correlated allele frequency model were used to analyse the dataset without prior population information for $K$ ranging from 2 to 10 . The program was run 20 times independently, and each run consisted of 1000000 Markov chain Monte Carlo (MCMC) iterations, after a burnin period of 100000 steps. Subsequently, an ad hoc quantity based on the second-order rate of change in the likelihood function with respect to $K(K)$ was used for estimating the number of clusters from structure analysis (Evanno et al. 2005). Structure Harvester v.0.6.1 (Earl $\delta$ VonHoldt 2011) was used to process the structure result files, and a graphical bar plot of membership coefficients for populations and individuals was generated using the DistRuct program (Rosenberg 2004).

To investigate an eventual spatial structure related to genetic differentiation considering, Barb, ArabBarb and both breeds together, a principal component analysis (PCA) was performed on allele frequencies averaged by regions (see Figure 1). On the basis of value for axis 1 of the PCA, results were then interpolated spatially, directly and using a Kriging approach, using the $\mathrm{R}$ procedure described by François (http:// membres-timc.imag.fr/Olivier.Francois/admix_display. html). Overall spatial correlation of PCA axis l was quantified and tested using Moran's I coefficient (Moran 1950), connecting regions with a Gabriel neighbouring graph.

\section{Results}

\section{Microsatellite markers}

All the equine microsatellites loci reported in this study have been amplified successfully in all breeds. A total number of 123 different alleles were detected across the 14 loci analysed. The number of alleles per locus $\left(A_{\mathrm{t}}\right)$ varied between 6 (HTG4) and 14 (ASB17) with a mean of 8.78 alleles (see Table S1). Moreover, the lower and higher values of allelic richness overall samples per locus $\left(R_{\mathrm{t}}\right)$ were showed in HTG6 (4.47) and $A S B 17$ (9.72) loci, respectively, with a mean of 6.86 . 
The expected heterozygosity across the breeds varied from 0.669 (HMSI) to 0.853 (VLH20), while the observed heterozygosity across the breeds ranged from 0.568 (HTG6) to 0.839 (HTG10).

Values for the Wright's F-statistics were determined after 10000 permutations (see Table S1), and multilocus $F_{\mathrm{ST}}$ values indicate that around $5 \%$ of the total genetic variation was attributed to significant differences between the horse breeds, with the remaining 95\% corresponding to differences between individuals. Genetic differentiation among breeds was highly significant $(\mathrm{p}<0.01)$ for all loci. A significant excess of homozygotes across all breeds $(\mathrm{p}<0.05)$ was found for HTG4 and ASB2 loci. On average, breeds had a $2.1 \%(\mathrm{p}<0.05)$ deficit of heterozygotes, whereas the total population had a $7 \%(\mathrm{p}<0.01)$ deficit of heterozygotes.

\section{Genetic diversity within breeds}

Parameters characterizing the polymorphism of all the horse breeds tested are listed in Table 1. The observed and expected heterozygosities per breed ranged from 0.72 (PS) to 0.752 (BA) and 0.71 (PS) to 0.77 (AB), respectively. The mean number of alleles $M N A$ was the highest in the Arab-Barb horses (7.86) and lowest in the Thoroughbred breed (5.71). F Is value within populations varied between -0.002 in the Barb and 0.057 in the Arab-Barb, although $F_{\text {IS }}$ was statistically significant only for Arab-Barb and Arabian breeds due to a deficiency of heterozygosity.

A total of 12 private alleles were identified in the present work, and most of the private alleles (eight) were at very low frequencies of below $2 \%$. Three alleles unique to Barb horses and one to a Thoroughbred horse showed a frequency that exceeded $2 \%$.

The HWE was tested for all breed-locus combinations. Significant $(p<0.05)$ deviations from a HWE were observed for $6(8.6 \%)$ of 70 breed-locus combinations. However, heterozygote deficiency analysis revealed that all the five populations exhibited significant deviation from HWE $(p<0.05)$ at many loci, The Arab-Barb horse showed the maximum number of loci in disequilibrium (5 loci), followed by Thoroughbred (three loci).

\section{Genetic variation and the relationship between Breeds}

The AMOva test revealed that the higher variation $(92.99 \%)$ is within the individual, $2 \%$ among individuals within populations and 5\% among populations.

All $F_{\mathrm{ST}}$ values calculated by pairwise breed combinations using FSTAT and after 5000 permutations were significantly different from zero $(\mathrm{p}<0.05)$. The highest level of differentiation was observed between Arabian and French Trotter breeds $\left(F_{\mathrm{ST}}=0.086\right)$ and the lowest one between Arab-Barb and Barb breeds $\left(F_{\mathrm{ST}}=0.001\right)$ (Table 2$) . N_{\mathrm{m}}$ represents the number of effective migrants exchanged per generation, Table 2 shows that the $N_{\mathrm{m}}$ values for pairs of breeds varied from 2.67 to 253.02 for the AR-TF pair and the ABBA pair, respectively. However, the effective number of migrants per generation $\left(N_{m}=253.02\right)$ between the Barb-Arab-Barb pair was very high in comparison with the values for the other pairs of breeds.

A neighbour-joining NJ tree was constructed on the basis of the $D_{R}$ genetic distances with relatively high bootstrap values (Figure 2). The tree showed a clear subdivision of the breeds and two groups can be distinguished. The first consisted of the $\mathrm{AB}$ and the $\mathrm{BA}$ identified with a high bootstrap value $(98.8 \%)$, and the second identified with a bootstrap value of $91.8 \%$ and was formed by PS and TF. The AR breed was identified between these two groups.

The factorial correspondence analysis FCA strongly confirmed the genetic distinctiveness of the five horse breeds. Results of the three-dimensional plot factorial correspondence analysis (Figure 3) clearly separated

Table 1 Basic information and values for parameter of polymorphism observed for each breed on the five populations studied

\begin{tabular}{|c|c|c|c|c|c|c|c|c|}
\hline \multirow[b]{2}{*}{ Population } & \multirow[b]{2}{*}{ Code } & \multirow[b]{2}{*}{ Sample size } & \multirow[b]{2}{*}{ MNA } & \multicolumn{2}{|l|}{ Heterozygosity } & \multirow[b]{2}{*}{$F_{I S}$} & \multicolumn{2}{|c|}{$\begin{array}{l}\text { Breed-specific } \\
\text { alleles }\end{array}$} \\
\hline & & & & $H_{\mathrm{O}}(\mathrm{SE})$ & $H_{\mathrm{e}}(\mathrm{SE})$ & & Breed & NPA \\
\hline Arab-Barb & $A B$ & 55 & 7.86 & $0.738(0.113)$ & $0.772(0.078)$ & $0.057 * \star$ & $A B$ & 3 \\
\hline Arabian & AR & 57 & 6.43 & $0.718(0.072)$ & $0.731(0.078)$ & $0.018^{*}$ & AR & 0 \\
\hline Barb & $\mathrm{BA}$ & 41 & 7.64 & $0.752(0.109)$ & $0.751(0.078)$ & -0.002 & $\mathrm{BA}$ & 5 \\
\hline Thoroughbred (Pur sang) & PS & 22 & 5.71 & $0.717(0.161)$ & $0.719(0.109)$ & 0.002 & PS & 2 \\
\hline French Trotter & TF & 26 & 6.07 & $0.723(0.151)$ & $0.723(0.118)$ & 0.000 & TF & 2 \\
\hline
\end{tabular}

$H_{0}$, observed heterozygosity; $H_{\mathrm{e}}$, expected heterozygosity; MNA, mean number of allele; $F_{\mathrm{IS}}$, heterozygote deficiency coefficient; NPA, number of private alleles; ${ }^{*} p<0.05,{ }^{*} p<0.01$. 
Table $2 F_{\text {ST }}$ estimates (below the diagonal) as a measure of genetic distance between horse breeds and the number of effective migrants per generation $N_{m}$ (above the diagonal)

\begin{tabular}{lllcll}
\hline Breed & AB & AR & BA & PS & TF \\
\hline AB & - & 6.92 & 253.02 & 3.61 & 3.85 \\
AR & 0.035 & - & 4.89 & 3.23 & 2.67 \\
BA & 0.001 & 0.048 & - & 2.93 & 3.88 \\
PS & 0.065 & 0.072 & 0.078 & - & 4.08 \\
TF & 0.060 & 0.086 & 0.060 & 0.057 & - \\
\hline
\end{tabular}

AB, Arab-Barb; AR, Arabian; BA, Barb; PS, Thoroughbred (Pur sang); TF, French Trotter.

the native populations from the other breeds. Simultaneously, the Barb and Arab-Barb were clustered together.

Bayesian clustering methods have proven to be powerful analytical tools for identifying genetic structure in data sets, Evanno et al. (2005) method, which is based on the second-order rate of change in the likelihood function with respect to $K(\Delta K)$, showed a clear peak at $K=3$. The Arabian (AR) breed was separated from the other populations after the first calculation clusters $(K=2)$. The Arab-Barb $(\mathrm{AB})$ and Barb (BA) breeds as well as the Thoroughbred (PS) and French Trotter (TF) breeds clustered together at $K=3$, when considering larger $K$ values, all breeds were separated into their own clusters (Figure 4), except for Barb and Arab-Barb.

\section{PCA and spatial interpolation of the results}

First axis of PCA performed on allele frequencies explained $17.8 \%, 18.7 \%$ and $16.7 \%$ of total inertia when considering Arab-Barb, Barb and both breeds grouped, respectively. Results of spatial interpolation based on first axis results are shown in Figure 5, indicating relative similarities between horses sampled Mascara, Saida and Tiaret (Tihirt). Note, however, that when computing spatial autocorrelation, Moran's I index was found significantly different from 0 only when considering both breed together $(p=0.01)$, with a value of 0.34 .

\section{Discussion}

In this paper, we carried out the first study applying molecular markers to characterize genetic variability of five horse breeds raised in Algeria. In addition, we resolved their genetic relationships, especially between autochthonous horse breeds Barb and ArabBarb.

All loci evaluated in the present work considered highly informative. The heterozygosities for all loci analysed were lower than expected (exception HMS6), which could be attributed to within-population inbreeding or by population subdivision (Wahlund's effects) (Arora \& Bhatia 2004). Rare alleles, with frequencies below 5\%, were found in all the breeds, exception the Arabian (Table 2). We have also observed a relatively large number of breedspecific alleles in Barb and Arab-Barb breeds. It was interesting to observe that while in Barb breed, $F_{\text {IS }}$ value was found non-significantly different from zero, in Arab-Barb breed, $F_{\text {IS }}$ was found significantly positive, which could be related to different breeding management methods in both breeds. Indeed, while in Barb breed, most of the stalions used are raised in one place (Haras national Tiaret), in ArabBarb breed, mating is managed independently by breeders all over the country, which could have led to some Wahlund's effects.

\footnotetext{
Figure 2 Neighbour-joining tree obtained from the $D_{R}$ distance between the studied populations (1000 bootstrap).
}

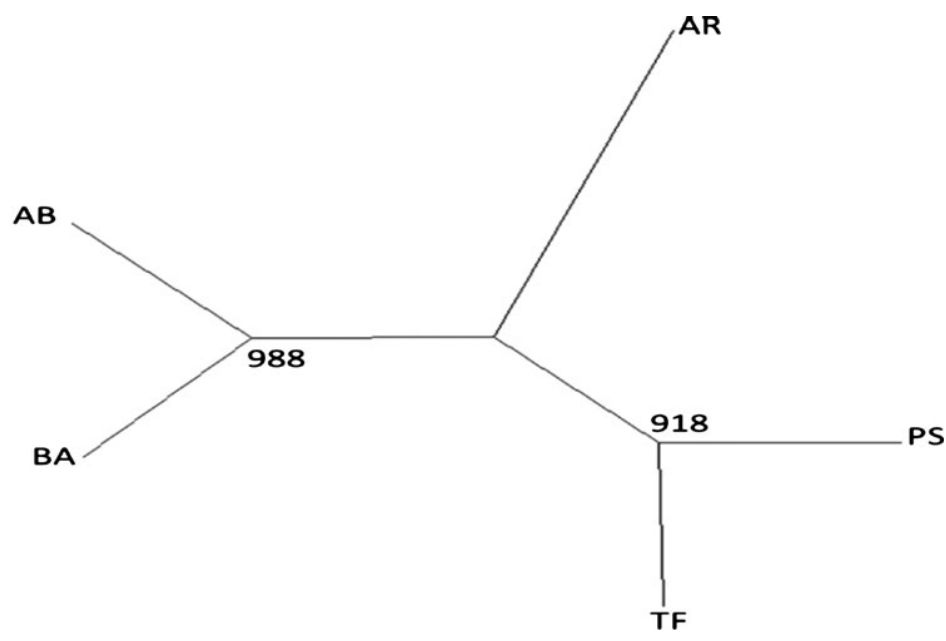



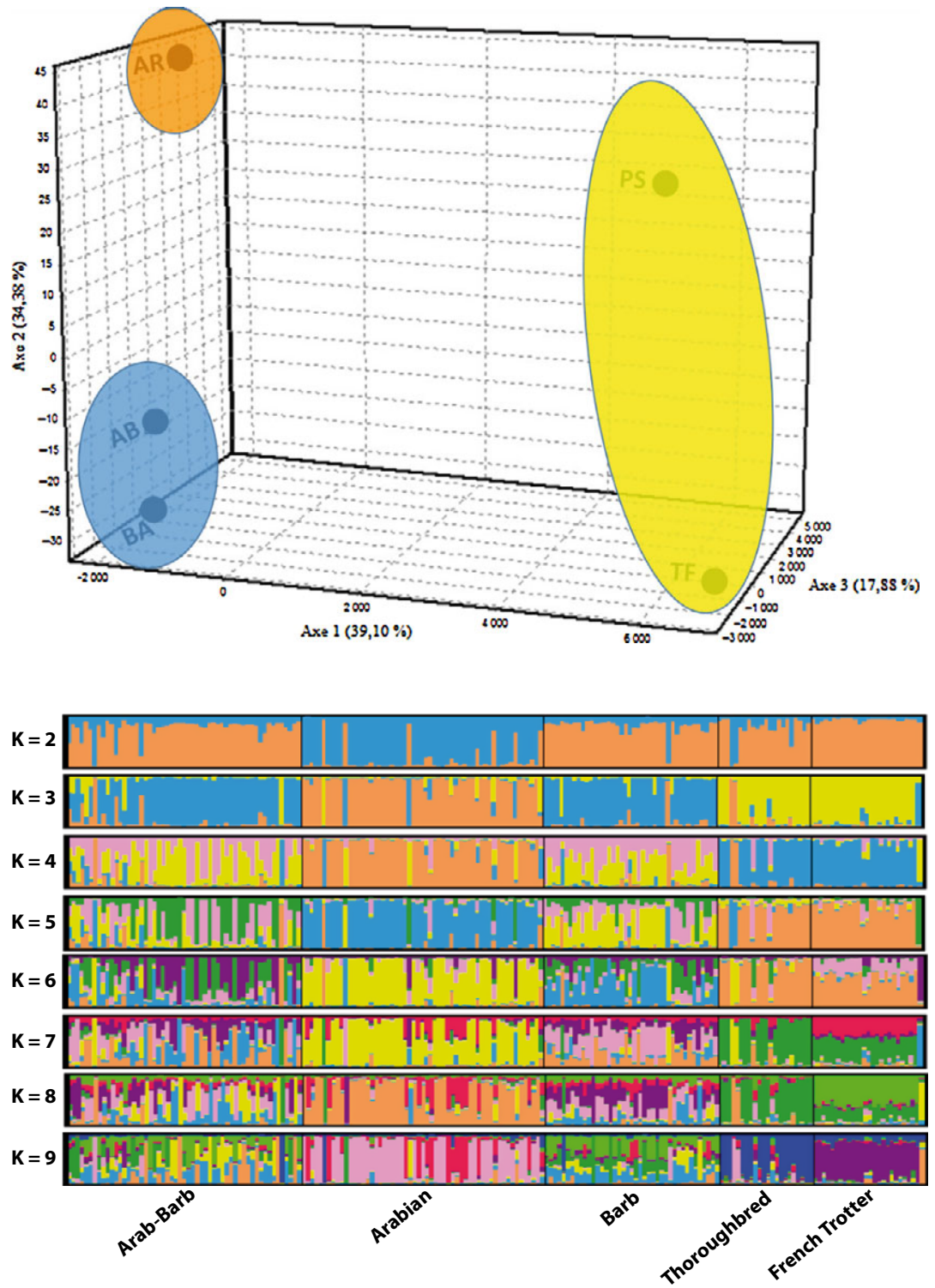

Figure 3 Factorial correspondence analysis of the 14 microsatellite loci analysed in the five horse breeds. Each individual was plotted into three-dimensional plot. Axis 1 accounts for $39.10 \%$ of the variation.
Our results showed genetic differentiation for all but Barb/Arab-Barb pairs of breeds. The level of differences explained $5 \%$ of the total genetic variation, and all loci contribute to this differentiation with $F_{S T}$ values being moderately low and similar for all systems studied, but very significant $(p<0.001)$. Our overall $F_{S T}$ value was similar to but slightly lower than the $6.5 \%$ reported by Behl et al. (2007) for five Indian horse breeds (Marwari, Spiti, Bhutia, Manipuri and Zanskari). However, it was smaller than those previously found in Polish breeds $\left(F_{\mathrm{ST}}=10 \%\right.$, Zabek et al. $2005)$, Brazilian breeds $\left(F_{\mathrm{ST}}=11.7 \%\right.$, Lippi \& Mortari $2003)$ and Norwegian breeds $\left(F_{\mathrm{ST}}=12 \%\right.$, Bjørnstad et al. 2000). The difference here is probably related to the fact that those studies investigated breeds from different origins (race/riding horse, heavy horses, ponies...), while here, all breeds analysed were all race horses explaining the lower $F_{\text {ST }}$ value.

All five populations (Arab-Barb, Arabian, Barb, Thoroughbred and French Trotter) had high heterozygosity values $(0.77,0.73,0.75,0.71$ and 0.72 , respectively). These values are among the highest heterozygosity values reported for other horse populations (Luís et al. 2007; Leroy et al. 2009; Khanshour et al. 2013), although these values are not directly comparable with these studies because of differences in the microsatellite sets used.

The divergence between the studied horse breeds was evaluated using different approaches (genetic distances, factorial correspondence analysis FCA and 

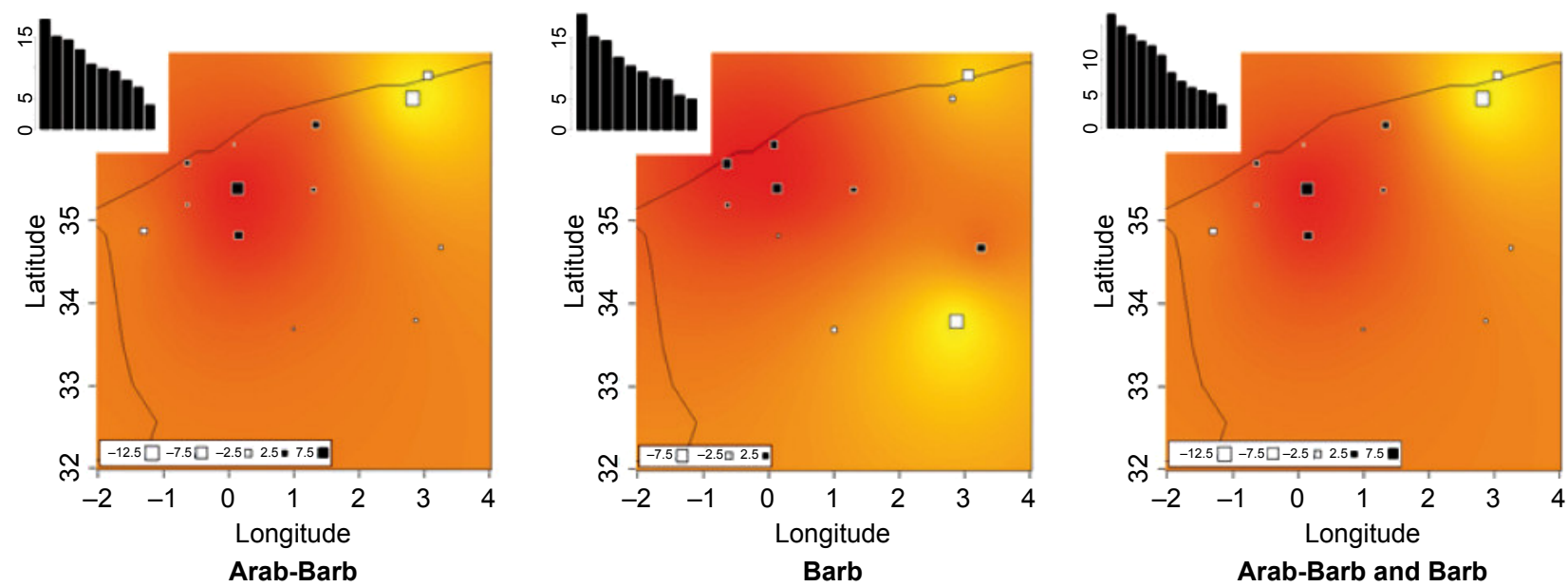

Figure 5 Geographical interpolation of principal component analysis (PCA) results for axis 1, considering Arab-Barb and Barb breeds independently or grouped (for each graph, eigenvalues for the 10 first axis are indicated).

clustering methods). All these three classical estimates based on genetic relationships gave similar results. There is a genetic differentiation between Algerian autochthonous horses and other breeds.

The neighbour-joining tree $\left(D_{\mathrm{R}}\right)$ showed a clear subdivision of the breeds, and Arab-Barb horse was more closely related to Barb Breed than the Arabian (Figure 2). Thoroughbred and French trotter breeds are clearly separated from the autochthonous breeds, and the Arabian horses assumed an intermediate position. This result could be explained by some influence from Arabian breed in the original breed formation in more recent years. The genetic proximity of both autochthonous breeds $\mathrm{BA}$ and $\mathrm{AB}$ was also demonstrated using the FCA and the Bayesian clustering approach, which gives more precise information on breed relationships. However, our estimates for the native breeds (BA and $\mathrm{AB}$ ) are similar to this reported by Ouragh et al. (1994), pointed out using biochemical polymorphisms.

Spatial interpolation may indicate some genetic differentiation related with geographical origins, even if those results should be taken with caution, as (i) Moran's index was found significantly different from 0 , only when considering Barb and Arab-Barb together, and (ii) first PCA's axis explained only $<20 \%$ of total inertia. A larger sampling considering the number of horses and markers used could provide more precise data on this question.

\section{Conclusion}

Summarizing the information above, we can conclude the genetic differentiation between Algerian autoch- thonous horses and other breeds. The $\mathrm{BA}$ and $\mathrm{AB}$ breeds appeared to be genetically related and considered as the same population. If these two breeds do not seem to show real differentiation based on microsatellite markers, which can be related to continuous gene flows between both populations, the different in genetic structure within both breeds may be eventually related to contrasted management methods. The data and information found here represent a preliminary to accomplish the genetic characterization of Algerian horse breeds.

\section{Acknowledgements}

We would like to thank the partners who have provided samples: the Haras National CHAOUCHAOUA of Tiaret and the National Office of the Development of Equine and Camel Livestock (ONDEEC), and we thank Mr. Benabdelmoumene S., Dr. Rahal K, Dr. Bouziane Z., Dr. Kébali A., Pr. Aumassip Kadri G. for their kind collaboration. We further acknowledge the staff of Labogena laboratory INRA - Jouy en Josas for their expert help in the genetic typing of horses.

\section{References}

Arora R., Bhatia S. (2004) Genetic structure of Muzzafarnagri sheep based on microsatellite analysis. Small Rumin. Res., 54, 227-230.

Behl R., Behl J., Gupta N., Gupta S.C. (2007) Genetic relationships of five Indian horse breeds using microsatellite markers. Animal, 1, 483-488.

Belkhir K., Borsa P., Chikhi L., Raufaste N., Bonhomme F. (2001) GENETIX 4.04, Logiciel sous Windows TM pour 
la Genetique des Populations. Laboratoire Genome, Populations, Interactions, CNRS UMR 5000, Universite' de Montpellier II, Montpellier, France.

Bjørnstad G., Gunby E., Røed K.H. (2000) Genetic structure of Norwegian horse breeds. J. Anim. Breed. Genet., 117, 307-317.

Bowling A.T., Eggleston Stott M.L., Byrns G., Clark R.S., Dileanis S., Wictum E. (1997) Validation of microsatellite markers for routine horse parentage testing. Anim. Genet., 28, 247-252.

Cañon J., Checa M.L., Carleos C., Vega-Pla J.L., Vallejo M., Dunner S. (2000) The genetic structure of Spanish Celtic horse breeds inferred from microsatellite data. Anim. Genet., 31, 39-48.

Earl D.A., VonHoldt B.M. (2011) STRUCTURE HARVESTER: a website and program for visualizing Structure output and implementing the Evanno method. Conserv. Genet. Resour., 4, 359-361.

Evanno G., Regnaut S., Goudet J. (2005) Detecting the number of clusters of individuals using the software Structure: a simulation study. Mol. Ecol., 14, 26112620.

Excoffier L., Laval G., Schneider S. (2005) Arlequin ver. 3.0: an integrated software package for population genetics data analysis. Evol. Bioinform. Online, 1, 47-50.

Felsenstein J. (1989) PHYLIP—Phylogeny Inference Package (Version 3.2). Cladistics, 5, 164-166.

François O. How to display admixture coefficients (Q matrix) spatially? (available at: http://membres timc. imag.fr/Olivier. Francois/admix_display.html).

Goudet J. (2001) FSTAT, A Program to Estimate and Test Gene Diversities and Fixation Indices (Version 2.9.3). Universite' de Lausanne, Lausanne, Suisse (available at: http://www2.unil.ch/popgen/softwares/fstat.htm last accessed 1 October 2011).

Huson D.H., Bryant D. (2006) Application of phylogenetic networks in evolutionary studies. Mol. Biol. Evol., 23, 254-267.

Kadri A. (2006) Le cheval barbe, cheval du Nord de l'Afrique, son rôle en Algérie. Organis. Mond. Cheval Barbe, 9 , 45.

Khanshour A., Conant E., Juras R., Cothran E.G. (2013) Microsatellite analysis of genetic diversity and population structure of Arabian horse populations. J. Hered., 3, 386-398.
Lebart L., Morineau A., Warwick K. (1984) Multivariate Descriptive Statistical Analysis. John Wiley, New York.

Leroy G., Verrier E., Meriaux J.C., Ricard A., Danchin Burge C., Rognon X. (2009) Genetic diversity of a large set of horse breeds raised in France assessed by microsatellite polymorphism. Genet. Sel. Evol., 41, 5.

Lippi A.S., Mortari N. (2003) Studies of blood groups and protein polymorphisms in the Brazilian horse breeds Mangalarga Marchador and Mangalarga (Equus caballus). Genet. Mol. Biol., 26, 431-434.

Luís C., Juras R., Oom M.M., Cothran E.G. (2007) Genetic diversity and relationships of Portuguese and other horse breeds based on protein and microsatellite loci variation. Anim. Genet., 38, 20-27.

Miller S.A., Dykes D.D., Polesky H.F. (1988) A simple salting out procedure for extracting DNA from human nucleated cells. Nucleic Acids Res., 16, 12-15.

Moran P.A.P. (1950) Notes on continuous stochastic phenomena. Biometrika, 37, 17-23.

Ouragh L., Meriaux J.C., Braun J.P. (1994) Genetic blood markers in Arabian, Barb and Arab-Barb horses in Morocco. Anim. Genet., 25, 45-47.

Pritchard J.K., Stephens M., Donnelly P. (2000) Inference of population structure using multilocus genotype data. Genetics, 155, 945-959.

Rahal K. (2005) Le barbe en Algérie, un acteur de développement durable des régions rurales. Le monde hippique, 48, 27-29.

Raymond M., Rousset F. (1995) GENEPOP (version 1.2). Population genetics software for exact tests and ecumenicism. J. Hered., 86, 248-249.

Rosenberg N.A. (2004) DISTRUCT: a program for the graphical display of population structure. Mol. Ecol. Notes, 4, 137-138.

Zabek T., Nogaj A., Radko A., Nogaj J., Slota E. (2005) Genetic variation of Polish endangered Bilgoraj horses and two common horse breeds in microsatellite loci. J. Appl. Genet., 46, 299-305.

\section{Supporting Information}

Additional Supporting Information may be found in the online version of this article:

Table S1 Descriptive statistics of the 14 microsatellite marker loci for all the studied breeds. 